\title{
Synthesis and Characterization of 2-Alkylbutadiene Polymers. II. Stereospecific Polymerization of 2-Ethyl-, 2- $n$-Propyl-, 2-Isopropyl-, and 2-n-Butylbutadienes
}

\author{
Ryotaro Ohno, Yasuyuki TanaKa, and Masato KaWaKami \\ Tokyo Research Laboratory, Japan Synthetic Rubber Co., Ltd., \\ Ikuta, Kawasaki, Kanagawa, Japan.
}

(Received March 22, 1972)

\begin{abstract}
Ethyl-, 2-n-propyl-, 2-isopropyl-, and 2-n-butylbutadienes were synthesized and polymerized by using stereospecific catalysts for isoprene polymerization, i.e., (a) $\mathrm{TiCl}_{4}-\mathrm{Al}\left(\mathrm{C}_{2} \mathrm{H}_{5}\right)_{3}-\mathrm{BF}_{3} 2 \mathrm{C}_{6} \mathrm{H}_{5} \mathrm{OH}$, (b) $n$-butyllthium/heptane, (c) $\mathrm{VOCl}_{3}-\mathrm{Al}\left(\mathrm{C}_{2} \mathrm{H}_{5}\right)_{3}$, and (d) $n$-butyllithlum/ethyl ether. It was found that poly(2-ethyl-, polyl(2-n-propy-, and poly(2-isopropylbutadiene)s prepared by the catalyst (a) were high-molecular-weight types having a rubber-like elasticity and consisted of predominantly cis-1,4 structure. The cis-1,4-unit content in the polymers prepared by the catalyst (a) decreased in the following sequence

$$
\text { methyl- } \cong \text { ethyl- }>n \text {-propyl- }>\text { isopropyl- } \gg n \text {-butyl- }
$$

in accordance with the decreasing order of the activity of this catalyst for these monomers. The polymers having $80-90 \%$ of cis-1,4 unit were obtained by the catalyst (b) except for $n$-butylbutadiene. On the other hand, no stereospecific polymers of trans-1,4 or 3,4 structure were obtained by the catalysts (c) and (d).

KEY WORDS 2-Ethylbutadiene / 2-n-Propylbutadiene / 2-Isopropylbutadiene / 2-n-Butylbutadiene / Stereospecific Polymerization / Isomeric Structure /
\end{abstract}

The polymerization of 2-substituted butadienes and the structure of the resulting polymers are of considerable interest in stereospecific polymerization as well as in the industrial use of polymers. In general, such substituted dienes can be polymerized to polymers having several types of structure, i.e., cis-1,4, trans-1,4, 3,4, and 1,2 structures. In the case of butadiene and isoprene, the relationship between the polymerization conditions and the isomericstructure of resulting polymers has been investigated in detail by many authors, and it is recognized that characterization of the isomericstructure is essential for predicting the physical and mechanical properties of the polymers.

Several reports have indicated that a number of 2-alkyl-substituted butadienes, such as 2-ethyl-, 2-n-propyl-, 2-tert-butyl, 2-n-amyl-, and 2-ndecylbutadienes can be polymerized by using peroxides, ${ }^{1,2}$ lithium compounds ${ }^{3}$ and Zieglertype catalysts. ${ }^{4-6}$ And in some cases, the glass transition temperature, ${ }^{1}$ mechanical properties ${ }^{2,3,7}$ and crystallinity ${ }^{4,5}$ of these polymers have been investigated. However, little was known about the determination of the isomeric structure in these polymers, and the relation between the substituted alkyl group and the properties of the resulting polymer.

In the previous paper ${ }^{8}$ dealing with the structural characterization of poly(2-ethyl-, poly(2-npropyl-, poly(2-isopropyl-, and poly(2-n-butylbutadiene)s, it was shown that the isomeric structure of these polymers could be determined by means of NMR spectroscopy. The present investigation was undertaken to elucidate the effects of substituents on the isomeric structure of poly(2-alkylbutadiene)s. With a view to obtaining stereospecific polymers in particular, the synthesis and polymerization of 2-ethyl-, 2-npropyl-, 2-isopropyl-, and 2-n-butylbutadienes were carried out by using several kinds of catalyst for stereospecific polymerization of 
isoprene.

\section{EXPERIMENTAL}

\section{Synthesis of 2-Alkylbutadienes}

2-Alkylbutadienes were prepared according to the following reaction sequence. ${ }^{9}$

$$
\begin{gathered}
\mathrm{RCH}_{2} \mathrm{CHO}+\mathrm{HCHO} \underset{\mathrm{NH}\left(\mathrm{CH}_{3}\right)_{2} \cdot \mathrm{HCl}}{\mathrm{CH}_{2}=\mathrm{CRCHO}}(1) \\
\mathrm{CH}_{2}=\mathrm{CRCHO}+\mathrm{CH}_{3} \mathrm{MgBr} \stackrel{\mathrm{H}_{2} \mathrm{O}}{\longrightarrow} \\
\mathrm{CH}_{2}=\mathrm{CRCH}\left(\mathrm{CH}_{3}\right) \mathrm{OH} \quad \text { (2) } \\
\mathrm{CH}_{2}=\mathrm{CRCH}\left(\mathrm{CH}_{3}\right) \mathrm{OH}+\left(\mathrm{CH}_{3} \mathrm{CO}\right)_{2} \mathrm{O} \longrightarrow \\
\mathrm{CH}_{2}=\mathrm{CRCH}\left(\mathrm{CH}_{3}\right) \mathrm{OCOCH} \mathrm{CH}_{3}
\end{gathered}
$$

$\alpha$-Alkylacroleins. $810 \mathrm{~g}(10.0 \mathrm{~mol})$ of dimethylamine hydrochloride, $750 \mathrm{~g}(10.0 \mathrm{~mol})$ of a $40-\%$ aqueous solution of formaldehyde, and $648 \mathrm{~g}$ $(9.00 \mathrm{~mol})$ of $n$-butyraldehyde were placed in a $5-l$ three-necked round-bottomed flask fitted with a reflux condenser, mechanical stirrer, and thermometer. The mixture was heated at $60^{\circ} \mathrm{C}$ and stirred for $6 \mathrm{hr}$, followed by steam distillation. The organic layer was dried over anhydrous magnesium sulfate and distilled.

$\alpha$-Ethyl acrolein: bp $91-92^{\circ} \mathrm{C}$; yield, $73 \%$.

Similarly other $\alpha$-alkyl acroleins were prepared from $n$-valeraldehyde, isovaleraldehyde, and $n$ amylaldehyde.

$\alpha$-n-Propylacrolein: bp $116-118^{\circ} \mathrm{C}$; yield, $77 \%$. $\alpha$-Isopropylacrolein: bp $109-110^{\circ} \mathrm{C}$; yield, $80 \%$. $\alpha$-n-Butylacrolein: bp $49-50^{\circ} \mathrm{C}(20 \mathrm{~mm})$; yield, $81 \%$.

2-Alkyl-3-hydroxy-1-butenes. $97.5 \mathrm{~g}(4.01 \mathrm{~mol})$ of magnesium turnings and $1 l$ of dry ether were placed under a nitrogen atmosphere in a $5-l$ three-necked round-bottomed flask fitted with a dropping funnel, reflux condenser, and mechanical stirrer. $582 \mathrm{~g}(4.10 \mathrm{~mol})$ of methyl iodide was added with stirring as rapidly as the reaction could be controlled. After formation of the Grignard complex, a solution of $269 \mathrm{~g}(3.20 \mathrm{~mol})$ of $\alpha$-ethylacrolein in $300 \mathrm{ml}$ of dry ether was added dropwise and then refluxed for $2 \mathrm{hr}$, followed by hydrolysis with saturated ammonium chloride solution and diluted sulfric acid. The ethereal layer was separated and dried over anhydrous magnesium sulfate, followed by distillation.

2-Ethyl-3-hydroxy-1-butene: bp $136^{\circ} \mathrm{C}$; yield, $81 \%$.

Other 2-alkyl-3-hydroxy-1-butenes were prepared in a similar manner to the above.

2-n-Propyl-3-hydroxy-1-butene: bp $80^{\circ} \mathrm{C} \quad(45$ $\mathrm{mmHg}$ ); yield, $90 \%$.

2-Isopropyl-3-hydroxy-1-butene: bp $84^{\circ} \mathrm{C} \quad(73$ $\mathrm{mm}$ ); yield, $87 \%$.

2-n-Butyl-3-hydroxy-1-butene: bp $65^{\circ} \mathrm{C}(53 \mathrm{~mm})$; yield, $90 \%$.

2-Alkyl-3-acetoxy-1-butenes. $68 \mathrm{~g}(0.68 \mathrm{~mol})$ of 2-ethyl-3-hydroxy-1-butene, $260 \mathrm{~g}(2.55 \mathrm{~mol})$ of acetic anhydride, and a few drops of pyridine were placed in a $500-\mathrm{m} l$ ampoule. The mixture was allowed to stand overnight in a steam bath. The reacted mixture was then neutralized with aqueous $\mathrm{Na}_{2} \mathrm{CO}_{3}$ and washed with distilled water. After drying over anhydous magnesium sulfate, the organic layer was distilled.

2-Ethyl-3-acetoxy-1-butene: bp $74^{\circ} \mathrm{C}(50 \mathrm{~mm})$; yield, $87 \%$.

Other 2-alkyl-3-acetoxy-1-butenes were prepared in a similar manner to the above.

2-n-Propyl-3-acetoxy-1-butene: bp $62-65^{\circ} \mathrm{C}(45$ $\mathrm{mm})$; yield, $80 \%$.

2-Isopropyl-3-acetoxy-1-butene: bp $62-65^{\circ} \mathrm{C}$ (23 mm); yield, 90\%.

2-n-Butyl-3-acetoxy-1-butene: bp $65^{\circ} \mathrm{C}(4 \mathrm{~mm})$; yield, $90 \%$.

2-Alkylbutadienes. The 2-ethylbutadiene was prepared by pyrolysis of $285 \mathrm{~g}(2.01 \mathrm{~mol})$ of 2ethyl-3-acetoxy-1-butene by passing it slowly through $30-\mathrm{mm}$ Pyrex tubing packed for a length of $25 \mathrm{~cm}$ with glass spirals and heated to $420^{\circ} \mathrm{C}$ by means of an electronic furnace. The resultant organic layer was separated, washed with water, and distilled after drying.

\section{2-Ethylbutadiene: bp $67^{\circ} \mathrm{C}$; yield, $31 \%$.}

Other 2-alkylbutadienes were prepared in a similar manner to the above. These 2-alkylbutadienes were purified by means of preparative 
gas chromatography.

2-n-Propylbutadiene: bp $92-93^{\circ} \mathrm{C}$; yield, $40 \%$. 2-Isopropylbutadiene: bp $85-86^{\circ} \mathrm{C}$; yield, $35 \%$. 2-n-Butylbutadiene: bp $57^{\circ} \mathrm{C}(85 \mathrm{~mm})$; yield, $47 \%$.

\section{Polymerization of 2-Alkylbutadienes}

Reagents. Pure 2-alkylbutadienes were redistilled just before use, dried over anhydrous calcium sulfate, and stored at $-30^{\circ} \mathrm{C}$ under a nitrogen atmosphere. The $\mathrm{Al}\left(\mathrm{C}_{2} \mathrm{H}_{5}\right)_{3}, \mathrm{TiCl}_{4}$, $\mathrm{VOCl}_{3}$, and $\mathrm{BF}_{2} 2 \mathrm{C}_{6} \mathrm{H}_{5} \mathrm{OH}$ were commercial products and were used without further purification. Toluene, hexane, heptane, and ethyl ether were purified in the usual way, dried over sodium wire, and stored under a nitrogen atmosphere.

Polymerization. Polymerizations by (a) $\mathrm{TiCl}_{4}-$ $\mathrm{Al}\left(\mathrm{C}_{2} \mathrm{H}_{5}\right)_{3}-\mathrm{BF}_{3} 2 \mathrm{C}_{6} \mathrm{H}_{5} \mathrm{OH}$, (b) n-butyllithium/ heptane, (c) $\mathrm{VOCl}_{3}-\mathrm{Al}\left(\mathrm{C}_{2} \mathrm{H}_{5}\right)_{3}$, and (d) $n$-butyllithium/ethyl ether were carried out in $50-\mathrm{m} l$ ampoules under a nitrogen atmosphere. These amouples were kept in a thermostatted bath with mechanical rotation for the desired time. The $\mathrm{TiCl}_{4}-\mathrm{Al}\left(\mathrm{C}_{2} \mathrm{H}_{5}\right)_{3}-\mathrm{BF}_{3} 2 \mathrm{C}_{6} \mathrm{H}_{5} \mathrm{OH}$ catalyst was prepared by reacting $\mathrm{TiCl}_{4}$ and $\mathrm{Al}\left(\mathrm{C}_{2} \mathrm{H}_{5}\right)_{3}$ $\mathrm{BF}_{3} 2 \mathrm{C}_{6} \mathrm{H}_{5} \mathrm{OH}$ in hexane at $0^{\circ} \mathrm{C}$ for $1 \mathrm{hr}$. The latter component was prepared beforehand by reacting $\mathrm{Al}\left(\mathrm{C}_{2} \mathrm{H}_{5}\right)_{3}$ with $\mathrm{BF}_{3} 2 \mathrm{C}_{6} \mathrm{H}_{5} \mathrm{OH}$ in hexane at $0^{\circ} \mathrm{C}$ for $10 \mathrm{~min}$. Crude polymers were purified by precipitation from benzene solution with methanol. The intrinsic viscosity was measured by using an Ubbelohde viscometer in toluene at $30^{\circ} \mathrm{C}$.

\section{RESULTS AND DISCUSSION}

(a) $\mathrm{TiCl}_{4}-\mathrm{Al}\left(\mathrm{C}_{2} \mathrm{H}_{5}\right)_{3}-\mathrm{BF}_{3} 2 \mathrm{C}_{6} \mathrm{H}_{5} \mathrm{OH}$, (b) nbutyllithium/heptane, (c) $\mathrm{VOCl}_{3}-\mathrm{Al}\left(\mathrm{C}_{2} \mathrm{H}_{5}\right)_{3}$, and (d) n-butyllithium/ethyl ether systems were typical stereospecific catalysts for isoprene polymerization, which gave polyisoprene having predominantly cis-1,4 ((a) and ((b)), trans-1,4 ((c)) and $3,4((d))$ structures, respectively. The polymerization conditions and the isomeric structure of the resulting polyisoprenes determined by the NMR method ${ }^{10}$ are listed in Table I. It is evident that the catalyst (a) is particularly appropriate for preparing cis-1,4 polyisoprene.

The polymerizations of 2-ethyl-, 2-n-propyl-, 2-isopropyl-, and 2-n-butylbutadienes were carried out using the same catalysts. The same $\mathrm{Al} / \mathrm{Ti}$ molar ratio as in the case of the polymerization of isoprene was chosen as with the catalyst (a) in order to compare the isomericstructures of the resulting polymers. The isomeric structures of these polymers were determined according to the NMR method presented in the previous paper. ${ }^{8}$ The results are given in Tables II-V.

Generally, the reactivity and stereospecificity of the catalysts for the stereospecific polymerization of isoprene are very different from those of butadiene. In the polymerization of these 2alkylbutadienes the catalysts (a) and (b), which give cis-1,4 polyisoprene as shown in Table I, gave also $c i s-1,4$ polymers of these monomers except for $n$-butylbutadiene. However, the polymers prepared by the catalyst (c) had somewhat lower trans-1,4 contents than those of the poly-

Table 耳. Polymerization of isoprene

\begin{tabular}{|c|c|c|c|c|c|c|c|c|c|c|c|}
\hline \multirow{2}{*}{\multicolumn{2}{|c|}{ Catalyst, }} & & \multirow{2}{*}{$\begin{array}{l}\text { Solvent, } \\
\mathrm{m} l\end{array}$} & \multirow{2}{*}{$\underset{{ }^{\circ} \mathrm{C}}{\mathrm{Temp}}$} & \multirow{2}{*}{$\underset{\mathrm{hr}}{\mathrm{Time}}$} & \multirow{2}{*}{$\begin{array}{l}\text { Yield, a } \\
\mathrm{g}\end{array}$} & \multirow{2}{*}{$\begin{array}{l}{[\eta],} \\
\mathrm{d} l / \mathrm{g}\end{array}$} & \multicolumn{4}{|c|}{ Isomeric structure, $\%$} \\
\hline & & nor & & & & & & $c i s-1,4$ & trans $-1,4$ & 3,4 & 1,2 \\
\hline \multirow[t]{3}{*}{ (a) } & $\mathrm{TiCl}_{4}$ & 0.05 & & & & & & & & & \\
\hline & $\left\{\mathrm{Al}\left(\mathrm{C}_{2} \mathrm{H}_{5}\right)_{3}\right.$ & 0.50 & Hexane & 10 & 5 & 3.20 & 5.50 & 98.0 & 0.2 & 1.8 & 0 \\
\hline & $\mathrm{BF}_{3} 2 \mathrm{C}_{6} \mathrm{H}_{5} \mathrm{OH}$ & 0.014 & 20 & & & & & & & & \\
\hline (b) & $n$-BuLi & 0.20 & $\begin{array}{l}\text { Heptane } \\
45\end{array}$ & 40 & 21 & 3.25 & 0.98 & 70.4 & 22.5 & 6.8 & 0 \\
\hline (c) & $\left\{\begin{array}{l}\mathrm{VOCl}{ }_{3} \\
\mathrm{Al}\left(\mathrm{C}_{2} \mathrm{H}_{5}\right)_{3}\end{array}\right.$ & $\begin{array}{l}0.10 \\
0.20\end{array}$ & $\begin{array}{c}\text { Toluene } \\
20\end{array}$ & 25 & 4 & 0.43 & 1.60 & 8.7 & 80.0 & 11.3 & 0 \\
\hline & $n-\mathrm{BuLi}$ & 0.20 & $\begin{array}{r}\mathrm{Et}_{2} \mathrm{O} \\
45\end{array}$ & 25 & 21 & 2.98 & 1.13 & \multicolumn{2}{|c|}{$19.0^{\mathrm{b}}$} & 74.8 & 6.2 \\
\hline
\end{tabular}

a Monomer, 3.40 g. b cis-1,4+trans $-1,4$. 
Polymerization of 2-Alkylbutadienes

Table II. Polymerization of 2-ethylbutadiene

\begin{tabular}{|c|c|c|c|c|c|c|c|c|c|c|c|}
\hline & \multirow{2}{*}{\multicolumn{2}{|c|}{ Catalyst, mmol }} & \multirow{2}{*}{$\begin{array}{l}\text { Solvent, } \\
\qquad \mathrm{m} l\end{array}$} & \multirow{2}{*}{$\underset{{ }^{\circ} \mathrm{C}}{\mathrm{Temp}}$} & \multirow{2}{*}{$\underset{\mathrm{hr}}{\mathrm{Time}}$} & \multirow{2}{*}{$\begin{array}{l}\text { Yield }^{\mathrm{a}} \\
\mathrm{g}\end{array}$} & \multirow{2}{*}{$\begin{array}{l}{[\eta]} \\
\mathrm{d} l / g\end{array}$} & \multicolumn{4}{|c|}{ Isomeric structure, $\%$} \\
\hline & & & & & & & & cis-1,4 & trans $-1,4$ & 3,4 & 1,2 \\
\hline \multirow[t]{3}{*}{ (a) } & $\mathrm{TiCl}_{4}$ & 0.25 & & & & & & & & & \\
\hline & $\left\{\mathrm{Al}\left(\mathrm{C}_{2} \mathrm{H}_{5}\right)_{3}\right.$ & 0.50 & Hexane & 10 & 5 & 4.26 & 4.40 & 98 & 0 & 2 & 0 \\
\hline & $\mathrm{BF}_{3} 2 \mathrm{C}_{6} \mathrm{H}_{5} \mathrm{OH}$ & 0.071 & 20 & & & & & & & & \\
\hline (b) & n-BuLi & 0.15 & $\begin{array}{c}\text { Heptane } \\
16\end{array}$ & 40 & 18 & 1.19 & 0.45 & 78 & 14 & 8 & 0 \\
\hline (c) & $\left\{\begin{array}{l}\mathrm{VOCl}_{3} \\
\mathrm{Al}\left(\mathrm{C}_{2} \mathrm{H}_{5}\right)_{3}\end{array}\right.$ & $\begin{array}{l}0.10 \\
0.20\end{array}$ & $\begin{array}{c}\text { Toluene } \\
20\end{array}$ & 25 & 18 & 0.19 & 0.24 & 39 & 53 & 8 & 0 \\
\hline (d) & $n$-BuLi & 0.15 & $\begin{array}{r}\mathrm{Et}_{2} \mathrm{O} \\
45\end{array}$ & 25 & 18 & 1.16 & 0.35 & & $58^{\mathrm{b}}$ & 42 & 0 \\
\hline
\end{tabular}

a Monomer: (a) $4.25 \mathrm{~g}$; (b), (d), $1.23 \mathrm{~g}$; (c), $2.16 \mathrm{~g} . \quad$ b cis-1,4+trans-1,4.

Table III. Polymerization of 2-n-propylbutadiene

\begin{tabular}{|c|c|c|c|c|c|c|c|c|c|c|c|}
\hline & \multirow{2}{*}{\multicolumn{2}{|c|}{ Catalyst, mmol }} & \multirow{3}{*}{$\begin{array}{l}\text { Solvent, } \\
\mathrm{m} l\end{array}$} & \multirow{3}{*}{$\underset{{ }^{\circ}}{\text { Temp }}$} & \multirow{3}{*}{$\underset{\mathrm{hr}}{\mathrm{Time}}$} & \multirow{3}{*}{$\begin{array}{c}\text { Yield, a } \\
\mathrm{g}\end{array}$} & \multirow{3}{*}{$\begin{array}{l}{[\eta]} \\
\mathrm{d} l / \mathrm{g}\end{array}$} & \multicolumn{4}{|c|}{ Isomeric structure, $\%$} \\
\hline & & & & & & & & $c i s-1,4$ & trans $-1,4$ & 3,4 & 1,2 \\
\hline \multirow{3}{*}{ (a) } & $\mathrm{TiCl}_{4}$ & 0.05 & & & & & & & & & \\
\hline & $\left\{\mathrm{Al}\left(\mathrm{C}_{2} \mathrm{H}_{5}\right)_{3}\right.$ & 0.10 & Hexane & 10 & 18 & 0.47 & 2.57 & 95 & 0 & 5 & 0 \\
\hline & $\mathrm{BF}_{3} 2 \mathrm{C}_{6} \mathrm{H}_{5} \mathrm{OH}$ & 0.014 & 4.2 & & & & & & & & \\
\hline (b) & $n$-BuLi & 0.10 & $\begin{array}{c}\text { Heptane } \\
18\end{array}$ & 40 & 18 & 1.31 & 0.46 & 91 & 4 & 5 & 0 \\
\hline (c) & $\left\{\begin{array}{l}\mathrm{VOCl}_{3} \\
\mathrm{~A} 1\left(\mathrm{C}_{2} \mathrm{H}_{5}\right)_{3}\end{array}\right.$ & $\begin{array}{l}0.05 \\
0.10\end{array}$ & $\begin{array}{c}\text { Toluene } \\
8\end{array}$ & 25 & 18 & 0.33 & 0.76 & 55 & 36 & 9 & 0 \\
\hline & $n$-BuLi & 0.10 & $\begin{array}{r}\mathrm{Et}_{2} \mathrm{O} \\
18\end{array}$ & 25 & 18 & 1.34 & 0.33 & \multicolumn{2}{|c|}{$57^{\mathrm{b}}$} & 43 & 0 \\
\hline
\end{tabular}

a Monomer: (a) $0.96 \mathrm{~g}$; (b)—(d), $1.44 \mathrm{~g}$. ' ${ }^{\mathrm{b}}$ cis-1,4+trans-1,4.

Table IV. Polymerization of 2-isopropylbutadiene

\begin{tabular}{|c|c|c|c|c|c|c|c|c|c|c|c|}
\hline & \multirow{2}{*}{\multicolumn{2}{|c|}{ Catalyst, mmol }} & \multirow{2}{*}{$\begin{array}{l}\text { Solvent, } \\
\mathrm{m} l\end{array}$} & \multirow{2}{*}{$\underset{{ }^{\circ} \mathrm{C}}{\mathrm{Temp}}$} & \multirow{2}{*}{$\underset{\mathrm{hr}}{\mathrm{Time}}$} & \multirow{2}{*}{$\begin{array}{c}\text { Yield, a } \\
\mathrm{g}\end{array}$} & \multirow{2}{*}{$\begin{array}{l}{[\eta],} \\
\mathrm{d} l / \mathrm{g}\end{array}$} & \multicolumn{4}{|c|}{ Isomeric structure, $\%$} \\
\hline & & & & & & & & $c i s-1,4$ & trans $-1,4$ & 3,4 & 1,2 \\
\hline \multirow[t]{3}{*}{ (a) } & $\mathrm{TiCl}_{4}$ & 0.05 & & & & & & & & & \\
\hline & $\left\{\mathrm{Al}\left(\mathrm{C}_{2} \mathrm{H}_{5}\right)_{3}\right.$ & 0.10 & Hexane & 10 & 18 & 0.48 & 3.88 & 91 & 9 & 0 & 0 \\
\hline & ${ }^{(} \mathrm{BF}_{3} 2 \mathrm{C}_{6} \mathrm{H}_{5} \mathrm{OH}$ & 0.014 & 4.2 & & & & & & & & \\
\hline (b) & n-BuLi & 0.10 & $\begin{array}{c}\text { Heptane } \\
18\end{array}$ & 40 & 18 & 1.34 & 0.90 & 86 & 10 & 4 & 0 \\
\hline (c) & $\left\{\begin{array}{l}\mathrm{VOCl}_{3} \\
\mathrm{Al}\left(\mathrm{C}_{2} \mathrm{H}_{5}\right)_{3}\end{array}\right.$ & $\begin{array}{l}0.05 \\
0.10\end{array}$ & $\begin{array}{c}\text { Toluene } \\
13\end{array}$ & 25 & 18 & 0.34 & - & \multicolumn{2}{|c|}{$90^{\mathrm{b}}$} & 10 & 0 \\
\hline & $n$-BuLi & 0.10 & $\begin{array}{r}\mathrm{Et}_{2} \mathrm{O} \\
18\end{array}$ & 25 & 18 & 1.38 & 0.32 & & $81^{\mathrm{b}}$ & 19 & 0 \\
\hline
\end{tabular}

a Monomer: (a) $0.96 \mathrm{~g}$; (b)-(d) $1.44 \mathrm{~g}$. b cis-1,4+trans-1,4.

isoprene prepared by the same catalyst. The same trend was observed in the 3,4 unit content in the polymers prepared by the catalyst (d).

Polymer J., Vol. 4, No. 1, 1973
In the case of the polymerization using the catalyst (a), the rate of polymerization decreased in the sequence 
Table V. Polymerization of 2-n-butylbutadiene

\begin{tabular}{|c|c|c|c|c|c|c|c|c|c|c|c|}
\hline \multirow{2}{*}{\multicolumn{2}{|c|}{ Catalyst, }} & mol & \multirow{2}{*}{$\begin{array}{l}\text { Solvent, } \\
\mathrm{m} l\end{array}$} & \multirow{2}{*}{ Temp } & \multirow{2}{*}{$\underset{\mathrm{hr}}{\mathrm{Time}}$} & \multirow{2}{*}{$\begin{array}{l}\text { Yield, }{ }^{\mathrm{a}} \\
\mathrm{g}\end{array}$} & \multirow{2}{*}{$\begin{array}{l}{[\eta]} \\
\mathrm{d} l / \mathrm{g}\end{array}$} & \multicolumn{4}{|c|}{ Isomeric structure, $\%$} \\
\hline & & 1101 & & & & & & cis-1,4 & trans $-1,4$ & 3,4 & 1,2 \\
\hline \multirow[t]{3}{*}{ (a) } & $\mathrm{TiCl}_{4}$ & 0.05 & & & & & & & & & \\
\hline & $\left\{\mathrm{Al}\left(\mathrm{C}_{2} \mathrm{H}_{5}\right)_{3}\right.$ & 0.10 & Hexane & 10 & 48 & 0.30 & 0.30 & 60 & 33 & 7 & 0 \\
\hline & $\mathrm{BF}_{3} 2 \mathrm{C}_{6} \mathrm{H}_{5} \mathrm{OH}$ & 0.014 & 5.2 & & & & & & & & \\
\hline (b) & $n$-BuLi & 0.10 & $\begin{array}{c}\text { Heptane } \\
20\end{array}$ & 40 & 18 & 1.45 & 0.50 & 62 & 35 & 3 & 0 \\
\hline (c) & $\left\{\begin{array}{l}\mathrm{VOCl}_{3} \\
\mathrm{Al}\left(\mathrm{C}_{2} \mathrm{H}_{5}\right)_{3}\end{array}\right.$ & $\begin{array}{l}0.10 \\
0.20\end{array}$ & $\begin{array}{c}\text { Toluene } \\
8.8\end{array}$ & 25 & 18 & 0.35 & - & 45 & 45 & 10 & 0 \\
\hline (d) & $n$-BuLi & 0.10 & $\begin{array}{l}\mathrm{Et}_{2} \mathrm{O} \\
20\end{array}$ & 25 & 18 & 1.47 & 0.46 & \multicolumn{2}{|c|}{$56^{b}$} & 44 & 0 \\
\hline
\end{tabular}

a Monomer: (a) $1.10 \mathrm{~g}$; (b)-(d) $1.65 \mathrm{~g}$. ' cis-1,4+trans-1,4.

methyl-@ethyl- $>n$-propyl-> isopropyl- $\gg n$-butyl-

This order is in accordance with the decreasing order in the content of cis-1,4 unit in the resulting polymers. It is noteworthy that this order is also the same as that of the bulkiness of the substituted alkyl group except for $n$ butylbutadiene. This suggests that the stereoregularity of the resulting polymers has a correlation with the rate of polymerization. It seems reasonable that the bulky substituents lower the selectivity and activity of a cis-1,4type monomer-catalyst-complex in the course of polymerization.

In the case of the catalyst (b), the cis-1,4-unit content amounted to about $90 \%$ in poly $(2-n$ propylbutadiene) and poly(2-isopropylbutadiene). The molecular weights of the polymers prepared by the catalyst (b) were much lower than those of the polymers prepared by the catalyst (a). As was reported in the case of polyisoprene, the isomeric structure of lithium-catalyzed polymers depends on the molecular weight of the samples. ${ }^{11}$ The stereospecificity of this catalyst was therefore not discussed further.

High-molecular-weight polymers of 2-ethyl-, 2-n-propyl-, and 2-isopropylbutadienes consisting of predominantly cis- 1,4 structure exhibit a rubber-like elasticity and could be cured using a standard sulfur recipe, whereas poly(2-n-butyl- butadiene)s are sticky solids. Contrary to the other 2-alkylbutadienes, 2- $n$-butylbutadiene gave no high cis-1,4 polymer using catalysts (a) and (b). This peculiarity with that monomer can not be explained at the present time.

\section{REFERENCES}

1. C. G. Overberger, L. H. Arond, R.H. Wiley, and R. G. Garret, J. Polym. Sci., 7, 431 (1951).

2. C. S. Marvel, J. L. R. Williams, and H. E. Baumgarten, ibid., 4, 583 (1949).

3. I. A. Livshits and L. M. Korobova, Vysokomol. Soedin., 3, 891 (1961).

4. W. Marconi, A. Mazzei, S. Cucinella, M. Cesari, and E. Pauluzzi, J. Polym. Sci., Part A, 3, 123 (1965).

5. W. Marconi, A. Mazzei, S. Cucinella, and M. Cesari, ibid., Part A, 2, 4261 (1964).

6. Goodyear Tire \& Rubber Co., British Patent 1004665 (1965).

7. I. A. Livshits, L. M. Korobova, and E. A. Sidorovich, Mekh. Polim., 596, (1964).

8. R. Ohno, M. Kawakami, and Y. Tanaka, Polymer J., 4, 49 (1973).

9. C. S. Marvel, R. L. Mayers, and J. H. Saunders, J. Am. Chem. Soc., 70, 1694 (1948).

10. Y. Tanaka, Y. Takeuchi, M. Kobayashi, and H. Tadokoro, J. Polym. Sci., Part A-2, 9, 43 (1971).

11. R. S. Sterns and L.E. Forman, ibid., 41, 381 (1959). 